Article

\title{
Evaluation of the Chemical and Mechanical Properties of Hardening High-Calcium Fly Ash Blended Concrete
}

\author{
Wei-Jie Fan, Xiao-Yong Wang * and Ki-Bong Park \\ Department of Architectural Engineering, Kangwon National University, Chuncheon-Si 200-701, \\ Korea; E-Mails: fanwjkw@gmail.com (W.-J.F.); kbpark@kangwon.ac.kr (K.-B.P.) \\ * Author to whom correspondence should be addressed; E-Mail: wxbrave @kangwon.ac.kr; \\ Tel.: +82-33-250-6229; Fax: +82-33-259-5542.
}

Academic Editor: Prabir Sarker

Received: 25 May 2015 / Accepted: 13 July 2015 / Published: 7 September 2015

\begin{abstract}
High-calcium fly ash (FH) is the combustion residue from electric power plants burning lignite or sub-bituminous coal. As a mineral admixture, FH can be used to produce high-strength concrete and high-performance concrete. The development of chemical and mechanical properties is a crucial factor for appropriately using FH in the concrete industry. To achieve sustainable development in the concrete industry, this paper presents a theoretical model to systematically evaluate the property developments of FH blended concrete. The proposed model analyzes the cement hydration, the reaction of free $\mathrm{CaO}$ in $\mathrm{FH}$, and the reaction of phases in $\mathrm{FH}$ other than free $\mathrm{CaO}$. The mutual interactions among cement hydration, the reaction of free $\mathrm{CaO}$ in $\mathrm{FH}$, and the reaction of other phases in $\mathrm{FH}$ are also considered through the calcium hydroxide contents and the capillary water contents. Using the hydration degree of cement, the reaction degree of free $\mathrm{CaO}$ in $\mathrm{FH}$, and the reaction degree of other phases in $\mathrm{FH}$, the proposed model evaluates the calcium hydroxide contents, the reaction degree of $\mathrm{FH}$, chemically bound water, porosity, and the compressive strength of hardening concrete with different water to binder ratios and FH replacement ratios. The evaluated results are compared to experimental results, and good consistencies are found.
\end{abstract}

Keywords: high calcium fly ash; hydration; kinetic model; calcium hydroxide; strength; concrete 


\section{Introduction}

Fly ash is produced in coal-burning electricity generation stations and has been widely used for producing high-performance concrete. Fly ashes can be divided into two categories according to their calcium content. The first type of fly ash, containing less than $10 \%$ analytical $\mathrm{CaO}$, is generally a product of the combustion of anthracite and bituminous coals. The second type of fly ash, typically containing $15 \%$ to $40 \%$ analytical $\mathrm{CaO}$, is generally a product of the combustion of lignite and sub-bituminous coals [1].

Many investigations on the physical, chemical, and durability properties of concrete incorporating low-calcium fly ash (FL, CaO less than 10\%) have been performed [2-6]. For concrete containing high-calcium fly ash (FH, $\mathrm{CaO}$ more than 10\%), the investigations are relatively insufficient. Due to the problems associated with the $\mathrm{FH}$ chemical compositions (high free $\mathrm{CaO}$ and sulfur contents), the suitability of FH as a mineral admixture in the concrete industry is viewed with skepticism. To overcome these problems and to apply FH blended concrete during dam construction, Tsimas and Moutsatsou-Tsima [7] put forward systematic industry methods. Untreated fly ash was cheaply upgraded by grinding at a specially designed ball mill with simultaneous hydration for the reduction of free $\mathrm{CaO}$. When the free calcium oxide content in FH is less than 3.5\% and the sulfur content in FH is less than $7 \%$, the soundness, performance, and durability of FH blended concrete can meet code specifications. Antiohos and Tsimas [8] investigated the role of the reactivity of reactive silica in the hydration of FH-cement blends. They found that after the first month of the hardening process, the soluble silica of FH holds a predominant role and that the silica is increasingly dissolved in the matrix, forming additional cementitious compounds with binding properties, principally a second generation calcium silicate hydrate (CSH). Erdogdu and Turker [9] investigated the effects of FH particle size distribution on the strength of FH-cement mortars. They found the reactivity of FH will increase with the increasing fineness and that the strength of FH blended mortar relates closely to the size fractions of FH. Summarily, experimental investigations [7-9] show that the properties of FH blended concrete relate to cement hydration and FH reaction. To evaluate the properties of FH blended concrete, both cement hydration and FH reaction should be considered.

Compared to the abundant experimental investigations on FL blended concrete [7-9], theoretical models for FH-cement blended concrete are very limited. Papadakis [10-12] proposed a simplified scheme describing the chemical reactions of the FH in FH-cement blends and developed mathematical expressions for predicting the final chemical and volumetric composition of FH blended concrete. Schindler and Folliard [13] described the heat evolution process of FH blended cement using a three-parameter model. The hydration time parameter, hydration shape parameter, and ultimate degree of hydration parameter are adopted for evaluating the hydration of concrete. Saeki and Monteiro [14] formulated a model to predict the reaction between calcium hydroxide and mineral admixtures (including high-calcium fly ash, low-calcium fly ash, and slag). The parameters of the prediction model are dependent on the physical and chemical characteristics of the mineral admixtures. Conversely, there are some limits for current models of FH blended concrete. Papadakis' model is only valid for hardened concrete and cannot be used to evaluate the properties development of hardening concrete [11,12]. Schindler and Folliard's model [13] is limited to evaluating the hydration heat of FH blended concrete. The interactions between cement hydration and FH reactions are not considered. Saeki and Monteiro's 
model [14] is useful for evaluating the calcium hydroxide content in hydrating cement-FH blends. However, other aspects related to the hydration process, such as chemically bound water, porosity, and compressive strength, cannot be determined using Saeki and Monteiro's model.

To overcome the limitations of the current models [11-14] and to systematically evaluate the chemical and mechanical properties development of FH blended concrete, this paper proposes a numerical model for hydrating cement-FH blends. The proposed model analyzes the cement hydration, the free $\mathrm{CaO}$ reaction in $\mathrm{FH}$, and the reaction of phases in $\mathrm{FH}$ other than free $\mathrm{CaO}$. The properties of hardening FH blended concrete, such as the reaction degrees of cement and $\mathrm{FH}$, the calcium hydroxide content, chemically bound water, porosity, and compressive strength, can be determined. To improve readability, the summary of abbreviations is shown in Table 1.

Table 1. Summary of abbreviations.

\begin{tabular}{|c|c|}
\hline Abbreviations & Text \\
\hline FH & high-calcium fly ash \\
\hline FL & low-calcium fly ash \\
\hline SF & silica fume \\
\hline $\mathrm{H}$ & $\mathrm{H}_{2} \mathrm{O}$ \\
\hline $\mathrm{C}$ & $\mathrm{CaO}$ \\
\hline$S$ & $\mathrm{SiO}_{2}$ \\
\hline A & $\mathrm{Al}_{2} \mathrm{O}_{3}$ \\
\hline $\mathrm{F}$ & $\mathrm{Fe}_{2} \mathrm{O}_{3}$ \\
\hline$\overline{\mathrm{S}}$ & $\mathrm{SO}_{3}$ \\
\hline $\mathrm{CF}$ & free $\mathrm{CaO}$ \\
\hline $\mathrm{CH}$ & $\mathrm{Ca}(\mathrm{OH})_{2}$ \\
\hline $\mathrm{C}_{3} \mathrm{~S}$ & $3 \mathrm{CaO} \cdot \mathrm{SiO}_{2}$ \\
\hline $\mathrm{C}_{2} \mathrm{~S}$ & $2 \mathrm{CaO} \cdot \mathrm{SiO}_{2}$ \\
\hline $\mathrm{C}_{3} \mathrm{~A}$ & $3 \mathrm{CaO} \cdot \mathrm{Al}_{2} \mathrm{O}_{3}$ \\
\hline $\mathrm{C}_{4} \mathrm{AF}$ & $4 \mathrm{CaO} \cdot \mathrm{Al}_{2} \mathrm{O}_{3} \cdot \mathrm{Fe}_{2} \mathrm{O}_{3}$ \\
\hline $\mathrm{CSH}$ & calcium silicate hydrate \\
\hline $\mathrm{A}-\mathrm{S}$ & aluminosilicate \\
\hline $\mathrm{C}-\mathrm{A}-\mathrm{S}$ & calcium aluminosilicate \\
\hline $\mathrm{C}-\mathrm{A}-\mathrm{H}$ & calcium aluminate hydrate \\
\hline $\mathrm{C}_{4} \mathrm{~A}_{3} \overline{\mathrm{S}}$ & monocalcium aluminosulfate \\
\hline FHA $10 \%$ & FH replaces aggregate by $10 \%$ weight of cement \\
\hline FHA20\% & FH replaces aggregate by $20 \%$ weight of cement \\
\hline FHA30\% & FH replaces aggregate by $30 \%$ weight of cement \\
\hline $\mathrm{FHC} 10 \%$ & FH replaces cement by $10 \%$ weight of cement \\
\hline FHC20\% & FH replaces cement by $20 \%$ weight of cement \\
\hline FHC $30 \%$ & FH replaces cement by $30 \%$ weight of cement \\
\hline TG/DTA & thermogravimetry/differential thermal analysis \\
\hline
\end{tabular}




\section{Hydration Model of Cement-FH Blends}

\subsection{Hydration Model of Cement}

In this study, the cement hydration model originally developed by Tomosawa [15] and modified by Park [16] is adopted to simulate the development of cement hydration. The kinetic processes of cement hydration, such as the formation and destruction of an initial impermeable layer, the activated chemical reaction process, and the following diffusion-controlled process, are considered in the modeling process $[15,16]$. This model is expressed as a single equation consisting of three coefficients: $k_{\mathrm{d}}$, the reaction coefficient in the induction period; $D_{\mathrm{e}}$, the effective diffusion coefficient of water through the $\mathrm{CSH}$ gel; and $k_{\mathrm{r}}$, a coefficient of the reaction rate of cement, as shown in Equation (1):

$$
\begin{gathered}
\frac{d \alpha}{d t}=\frac{3\left(S_{\mathrm{w}} / S_{0}\right) \rho_{\mathrm{w}} C_{\mathrm{w}-\text { free }}}{\left(v+w_{\mathrm{g}}\right) r_{0} \rho_{\mathrm{c}}} \frac{1}{\left(\frac{1}{k_{\mathrm{d}}}-\frac{r_{0}}{D_{\mathrm{e}}}\right)+\frac{r_{0}}{D_{e}}(1-\alpha)^{\frac{-1}{3}}+\frac{1}{k_{\mathrm{r}}}(1-\alpha)^{\frac{-2}{3}}} \\
k_{\mathrm{d}}=\frac{B_{\mathrm{ce}}}{\alpha^{1.5}}+C_{\mathrm{ce}} \alpha^{3} \\
D_{\mathrm{e}}=D_{\mathrm{e} 0} \ln \left(\frac{1}{\alpha}\right)
\end{gathered}
$$

where $\alpha$ is the degree of cement hydration; $v$ is the stoichiometric ratio by mass of water to cement $(=0.25) ; w_{\mathrm{g}}$ is the physically bound water in the CSH gel $(=0.15) ; \rho_{\mathrm{w}}$ is the density of water; $C_{\mathrm{w}-\text { free }}$ is the amount of water at the exterior of the $\mathrm{CSH}$ gel; $r_{0}$ is the radius of unhydrated cement particles $\left(r_{0}=3 /\left(S \rho_{\mathrm{c}}\right)\right.$, in which the terms $S$ and $\rho_{\mathrm{c}}$ stand for the Blaine surface area and the density of the cement, respectively); $S_{\mathrm{w}}$ is the effective surface area of the cement particles in contact with water and $S_{0}$ is the total surface area if the surface area develops unconstrained; $B_{\text {ce }}$ controls the rate of the initial shell formation and $C_{\mathrm{ce}}$ controls the rate of the initial shell decay; and $D_{\mathrm{e} 0}$ is the initial value of the effective diffusion coefficient.

The amount of water in the capillary pores $C_{\mathrm{w} \text {-free }}$ is expressed as a function of the degree of hydration in the previous step, as shown in Equation (1d):

$$
C_{\mathrm{w}-\text { free }}=\frac{W_{0}-0.4 * \alpha * C_{0}}{W_{0}}
$$

where $C_{0}$ and $W_{0}$ are the mass fractions of cement and water in the mix proportion.

The effect of temperature on the reaction coefficients is assumed to follow Arrhenius's law [15,16]. Using the proposed Portland cement hydration model, Tomosawa [15] evaluated the heat evolution rate, chemically bound water, and compressive strength of hardening concrete. Park et al. [16] predicted the temperature distribution in ultra-high-strength concrete using this hydration model. A good correlation was found between the analysis results and the experimental results.

\subsection{Reaction of Free $\mathrm{CaO}$ in $\mathrm{FH}$}

Cement notation chemistry is used throughout this paper, where $\mathrm{H}: \mathrm{H}_{2} \mathrm{O}, \mathrm{C}: \mathrm{CaO}, \mathrm{S}: \mathrm{SiO}_{2}, \mathrm{~A}: \mathrm{Al}_{2} \mathrm{O}_{3}$, $\mathrm{F}: \mathrm{Fe}_{2} \mathrm{O}_{3}, \overline{\mathrm{S}}: \mathrm{SO}_{3}, \mathrm{CH}: \mathrm{Ca}(\mathrm{OH})_{2}$. For $\mathrm{FH}$, the majority of calcium is present in crystalline and reactive constituents, such as $\mathrm{C}_{3} \mathrm{~A}, \mathrm{C}_{4} \mathrm{~A}_{3} \overline{\mathrm{S}}, \mathrm{C} \overline{\mathrm{S}}$, free $\mathrm{CaO}$, and calcium aluminosilicate $(\mathrm{C}-\mathrm{A}-\mathrm{S})$ glass. Free $\mathrm{CaO}$ 
has both negative and positive effects on concrete performance. Free $\mathrm{CaO}$ can harm the volume stability and the concrete durability [1]. Conversely, some researchers state that a moderate amount of free $\mathrm{CaO}$ (3.5\% free $\mathrm{CaO}$ ) is essential for the initial activation of high calcium fly ash [7]. The free $\mathrm{CaO}$ is hydrated rapidly to $\mathrm{CH}$ as follows [11]:

$$
\mathrm{C}+\mathrm{H} \rightarrow \mathrm{CH}
$$

Chen [17] studied the hydration kinetic process of free $\mathrm{CaO}$ in systems containing high-calcium fly ash- $\mathrm{H}_{2} \mathrm{O}$ at different curing temperatures. The reaction of free $\mathrm{CaO}$ in $\mathrm{FH}$ is a first-order reaction whose rate is directly proportional to the degree of reaction. Chen [17] proposed that the reaction degree of free $\mathrm{CaO} \alpha_{\mathrm{CF}}$ can be described as follows:

$$
\alpha_{\mathrm{CF}}(t)=1-\frac{1}{e^{k t}}
$$

where $k$ is reaction rate coefficient $\left(k\right.$ is $0.09 / \mathrm{h}$ when the temperature is $20^{\circ} \mathrm{C}$, and the dependence of the reaction rate coefficient on the curing temperature can be described using Arrhenius's law [17]).

\subsection{Reaction of Phases in FH other than Free $\mathrm{CaO}$}

FH essentially consists of aluminosilicate glass modified by the presence of large amounts of calcium and magnesium. High-calcium fly ashes are pozzolans that will react with the calcium hydroxide resulting from the hydration of Portland cement to produce calcium silicate hydrate (CSH) and calcium aluminate hydrate $(\mathrm{C}-\mathrm{A}-\mathrm{H})$. However, $\mathrm{FH}$ are also hydraulic in nature, as they will react directly with water to form a range of hydration products, and a mix of FH and water will set, harden, and gain a certain strength even in the absence of Portland cement (or other activators). This behavior results from the hydraulic nature of the crystalline products and the dissolution and reaction of the glass due to the presence of soluble alkalis and calcium within the FH [10-12]. Therefore, high-calcium fly ash has both hydraulic properties and pozzolanic properties.

Saeki and Monteiro [14] proposed that the reaction between FH and calcium hydroxide is a diffusion-controlled process. The reaction rate of $\mathrm{FH}$ relates to the available calcium hydroxide content in a cement-FH system. Giergiczny [18] investigated the hydraulic activity of FH using an isothermal heat evolution experiment. Similar to cement, the reaction process of an FH-water paste consists of an initial dormant period, a phase boundary reaction process, and a diffusion process. Papadakis [12] proposed that similar to the control of Portland cement, the strength of FH blended concrete relates to the calcium silicate hydrate (CSH) content. Similar to cement, the reaction products of high-calcium fly ash adhere to the surfaces of the remaining FH particles. Therefore, in this paper, similar to that of Portland cement, the reaction of FH is assumed to consist of three processes: an initial dormant period, a phase boundary reaction process, and a diffusion process. The reaction equations of $\mathrm{FH}$ are originally proposed as follows:

$$
\begin{gathered}
\frac{d \alpha_{\mathrm{FH}}}{d t}=\frac{m_{\mathrm{CH}}(t)}{P} \frac{W_{\mathrm{cap}}}{W_{0}} \frac{3 \rho_{\mathrm{w}}}{v_{\mathrm{FH}} r_{0 \mathrm{FH}} \rho_{\mathrm{FH}}} \frac{1}{\left(\frac{1}{k_{\mathrm{dFH}}}-\frac{r_{0 \mathrm{FH}}}{D_{\mathrm{eFH}}}\right)+\frac{r_{0 \mathrm{FH}}}{D_{\mathrm{eFH}}}\left(1-\alpha_{\mathrm{FH}}\right)^{\frac{-1}{3}}+\frac{1}{k_{\mathrm{FFH}}}\left(1-\alpha_{\mathrm{FH}}\right)^{\frac{-2}{3}}} \\
k_{\mathrm{dFH}}=\frac{B_{\mathrm{FH}}}{\alpha_{\mathrm{FH}}{ }^{1.5}}+C_{\mathrm{FH}} \alpha_{\mathrm{FH}}{ }^{3} \\
D_{\mathrm{eFH}}=D_{\mathrm{e} 0 \mathrm{FH}} \ln \left(\frac{1}{\alpha_{\mathrm{FH}}}\right)
\end{gathered}
$$


where $\alpha_{\mathrm{FH}}$ is the reaction degree of the active part in $\mathrm{FH}$ other than free $\mathrm{CaO}, m_{\mathrm{CH}}(t)$ is the mass of calcium hydroxide, $W_{\text {cap }}$ is the mass of capillary water, $P$ is the quality of the $\mathrm{FH}$ in the mixing proportion other than the mass of free $\mathrm{CaO}, v_{\mathrm{FH}}$ is the stoichiometry ratio by mass of $\mathrm{CH}$ to $\mathrm{FH}$ other than free $\mathrm{CaO}$, $r_{0 \mathrm{FH}}$ is the radius of the $\mathrm{FH}$ particle, $\rho_{\mathrm{FH}}$ is the density of $\mathrm{FH}, k_{\mathrm{dFH}}$ is the reaction rate coefficient in the dormant period ( $B_{\mathrm{FH}}$ and $C_{\mathrm{FH}}$ are coefficients), $k_{\mathrm{rFH}}$ is the reaction rate coefficient of the phase boundary reaction process, and $D_{\mathrm{e} 0 \mathrm{FH}}$ is the initial diffusion coefficient.

Papadakis [11] proposed that FH consists of an active part and an inert part. The active part includes an aluminosilicate glass phase, a calcium phase, and a sulfate phase. The reacted ratio of the active part of $\mathrm{FH}$ other than free $\mathrm{CaO}$ can be calculated according to Equation (4a) through (4c). The crystalline part of alumina found in corundum and $\mathrm{A}_{3} \mathrm{~S}_{2}$ will not react. The non-reactive part of silica is present in quartz and in crystalline A-S phases. The inert part is assumed to be chemically inert and does not react. The reacted ratio of $\mathrm{FH}$ other than free $\mathrm{CaO}$ (including both an active part and an inert part) can be obtained based on Equation (4a) through (4c) and the mass compositions of the fly ash. Considering both the active part and the inert part, the total reaction degree of $\mathrm{FH}$ other than free $\mathrm{CaO}$ can be determined as follows:

$$
\alpha_{\mathrm{FH}-\text { total }}=\gamma_{\mathrm{active}} \times \alpha_{\mathrm{FH}}
$$

where $\alpha_{\mathrm{FH}-\text { total }}$ is the reactive degree of the total $\mathrm{FH}$ other than free $\mathrm{CaO}$ and $\gamma_{\text {active }}$ is the weight fraction of the active part of $\mathrm{FH}$ other than free $\mathrm{CaO}$.

\subsection{Mutual Interactions among Cement Hydration, the Reaction of Free CaO in FH, and the Reaction of Phases in $\mathrm{FH}$ other than Free $\mathrm{CaO}$}

As proposed by Papadakis [11], the chemical reactions of the mineral compounds of Portland cement can be expressed as follows:

$$
\begin{gathered}
2 \mathrm{C}_{3} \mathrm{~S}+6 \mathrm{H} \rightarrow \mathrm{C}_{3} \mathrm{~S}_{2} \mathrm{H}_{3}+3 \mathrm{CH} \\
2 \mathrm{C}_{2} \mathrm{~S}+4 \mathrm{H} \rightarrow \mathrm{C}_{3} \mathrm{~S}_{2} \mathrm{H}_{3}+\mathrm{CH} \\
\mathrm{C}_{3} \mathrm{~A}+\mathrm{C} \overline{\mathrm{SH}} \mathrm{H}_{2}+10 \mathrm{H} \rightarrow \mathrm{C}_{4} \mathrm{~A} \overline{\mathrm{S}} \mathrm{H}_{12} \\
\mathrm{C}_{4} \mathrm{AF}+2 \mathrm{CH}+10 \mathrm{H} \rightarrow \mathrm{C}_{6} \mathrm{AFH}_{12}
\end{gathered}
$$

FH has a composition closer to Portland cement than low-calcium fly ash (FL) or silica fume (SF). The active part of FH consists of an aluminosilicate glass phase, a calcium phase, and a sulfate phase. The majority of the active part of the silica in $\mathrm{FH}$ is present in aluminosilicate (A-S) and calcium aluminosilicate $(\mathrm{C}-\mathrm{A}-\mathrm{S})$ glass. Calcium silicate hydrate $(\mathrm{CSH})$ is formed from the pozzolanic action of the reactive silica of $\mathrm{FH}$ as follows [11]:

$$
2 \mathrm{~S}+3 \mathrm{CH} \rightarrow \mathrm{C}_{3} \mathrm{~S}_{2} \mathrm{H}_{3}
$$

Part of alumina, found as tricalcium aluminate $\left(\mathrm{C}_{3} \mathrm{~A}\right)$ and monocalcium aluminosulfate $\left(\mathrm{C}_{4} \mathrm{~A}_{3} \overline{\mathrm{S}}\right)$, reacts with water, $\mathrm{CH}$, and/or gypsum, as in cement hydration, showing these high early strengths. This reaction in an excess of sulfate ions (as applies in this case) can be totally described as follows [11]:

$$
\mathrm{C}_{3} \mathrm{~A}+\mathrm{C} \overline{\mathrm{S}} \mathrm{H}_{2}+10 \mathrm{H} \rightarrow \mathrm{C}_{4} \mathrm{~A} \overline{\mathrm{S}} \mathrm{H}_{12}
$$


The crystalline part of alumina found in corundum and $\mathrm{A}_{3} \mathrm{~S}_{2}$ will not react. The rest of the alumina present in A-S and C-A-S glass is expected to react as follows [11]:

$$
\mathrm{A}+\mathrm{C} \overline{\mathrm{S}} \mathrm{H}_{2}+3 \mathrm{CH}+7 \mathrm{H} \rightarrow \mathrm{C}_{4} \mathrm{AH}_{12}
$$

The Portland cement and $\mathrm{FH}$ can be analyzed in terms of oxides: total $\mathrm{CaO}(\mathrm{C})$, free $\mathrm{CaO}(\mathrm{CF}), \mathrm{SiO}_{2}$ (S), $\mathrm{Al}_{2} \mathrm{O}_{3}(\mathrm{~A}), \mathrm{Fe}_{2} \mathrm{O}_{3}(\mathrm{~F}), \mathrm{SO}_{3}(\overline{\mathrm{S}})$, and other oxides or impurities denoted by R. Let fi,c and fi,p denote the weight fractions of the constituent $i(i=\mathrm{C}, \mathrm{CF}, \mathrm{S}, \mathrm{A}, \mathrm{F}, \overline{\mathrm{S}}, \mathrm{R})$ in the cement and FH other than free $\mathrm{CaO}$, respectively. Let $\gamma_{\mathrm{S}}$ and $\gamma_{\mathrm{A}}$ denote the active fraction of the oxides $\mathrm{S}$ and $\mathrm{A}$ in the $\mathrm{FH}$, respectively. Considering the production of calcium hydroxide from cement hydration and the reaction of free $\mathrm{CaO}$ in $\mathrm{FH}$, the consumption of calcium hydroxide from the reaction of phases in $\mathrm{FH}$ other than free $\mathrm{CaO}$, and the content of calcium hydroxide in FH-cement blends can be determined as follows:

$$
\begin{gathered}
C H(t)=C_{0} R C H_{\mathrm{CE}} \alpha+1.321 C F(t)-v_{\mathrm{FH}} \alpha_{\mathrm{FH}} P \\
v_{\mathrm{FH}}=\left(1.851 \gamma_{\mathrm{S}} f_{S, p}+2.182 \gamma_{\mathrm{A}} f_{\mathrm{A}, \mathrm{p}}\right)-1.321\left(f_{\mathrm{C}, \mathrm{p}}-0.7 f_{\overline{\mathrm{S}}, \mathrm{p}}\right) \\
C F(t)=C F_{0} \alpha_{\mathrm{CF}}(t)
\end{gathered}
$$

where $R C H_{C E}$ is the produced calcium hydroxide from 1 gram of cement, $C F(t)$ is the mass of the reacted free $\mathrm{CaO}$ at time $t$, and $C F_{0}$ is the mass of the free $\mathrm{CaO}$ content in $\mathrm{FH}$. The term $C_{0} R C H_{\mathrm{CE}} \alpha$ considers the production of calcium hydroxide from cement hydration, the term $1.321 C F(t)$ considers the production of calcium hydroxide from the reaction of free $\mathrm{CaO}$ in $\mathrm{FH}$, and the term $-v_{\mathrm{FH}} \alpha_{\mathrm{HF}} P$ considers the consumption of calcium hydroxide from the reaction of phases in $\mathrm{FH}$ other than free $\mathrm{CaO}$.

Similarly, the mass of calcium silicate hydrate (CSH) relates to the cement hydration and $\mathrm{FH}$ reaction. The mass of CSH can be determined as follows:

$$
\left.\mathrm{C} S H(t)=2.85 f_{\mathrm{S}, \mathrm{c}} \alpha C_{0}+\gamma_{\mathrm{S}} f_{\mathrm{S}, \mathrm{p}} \alpha_{\mathrm{FH}} P\right)
$$

where $2.85 f_{\mathrm{S}, \mathrm{c}} \alpha C_{0}$ considers the production of $\mathrm{CSH}$ from cement hydration, and $2.85 \gamma_{\mathrm{S}} f_{\mathrm{S}, \mathrm{p}} \alpha_{\mathrm{FH}} P$ considers the production of CSH from the $\mathrm{FH}$ reaction.

The mass of chemically bound water relates to the cement hydration, the reaction of free $\mathrm{CaO}$ in $\mathrm{FH}$, and the reaction of phases in $\mathrm{FH}$ other than free $\mathrm{CaO}$. The mass of chemically bound water $W_{\text {cbm }}$ can be determined as follows:

$$
W_{\mathrm{cbm}}=v \times C_{0} \times \alpha+R C W_{\mathrm{FH}} \times \alpha_{\mathrm{FH}} \times P+0.321 C F(t)
$$

where $R C W_{\mathrm{FH}}$ is the mass of chemically bound water from 1 gram of reacted $\mathrm{FH}\left(R C W_{\mathrm{FH}}=0.09\right.$ [11]). The term $v \times C_{0} \times \alpha$ denotes the production of chemically bound water from cement hydration, the term $0.321 C F(t)$ denotes the production of chemically bound water from the reaction of free $\mathrm{CaO}$ in $\mathrm{FH}$, and the term $R C W_{\mathrm{FH}} \times \alpha_{\mathrm{FH}} \times P$ denotes the production of chemically bound water from the reaction of phases in $\mathrm{FH}$ other than free $\mathrm{CaO}$.

The mass of capillary water relates to the cement hydration, the reaction of free $\mathrm{CaO}$ in $\mathrm{FH}$, and the reaction of phases in $\mathrm{FH}$ other than free $\mathrm{CaO}$. The mass of capillary water $W_{\text {cap }}$ can be calculated as follows:

$$
W_{\text {cap }}=W_{0}-0.4 \times C_{0} \times \alpha-R C W_{\mathrm{FH}} \times \alpha_{\mathrm{FH}} \times P-0.321 C F(t)-R P W_{\mathrm{FH}} \times \alpha_{\mathrm{FH}} \times P
$$


where $R P W_{\mathrm{FH}}$ is the mass of physically bound water from 1 gram of reacted $\mathrm{FH}\left(R P W_{\mathrm{FH}}=0.15[11]\right)$. The term $R P W_{\mathrm{FH}} \times \alpha_{\mathrm{FH}} \times P$ denotes the consumption of physically bound water from the reaction of phases in $\mathrm{FH}$ other than free $\mathrm{CaO}$.

The porosity of hydrating blends is reduced due to the Portland cement hydration, the reaction of free $\mathrm{CaO}$ in $\mathrm{FH}$, and the reaction of phases in $\mathrm{FH}$ other than free $\mathrm{CaO}$. The porosity, $\varepsilon$, can be estimated as follows:

$$
\varepsilon=\frac{W}{\rho_{\mathrm{W}}}-\Delta \varepsilon_{\mathrm{c}}-\Delta \varepsilon_{\mathrm{CF}}-\Delta \varepsilon_{\mathrm{FH}}
$$

where $\Delta \varepsilon_{\mathrm{c}}, \Delta \varepsilon_{\mathrm{CF}}$, and $\Delta \varepsilon_{\mathrm{FH}}$ are the porosity reduction due to the Portland cement hydration, the reaction of free $\mathrm{CaO}$ in $\mathrm{FH}$, and the reaction of phases in $\mathrm{FH}$ other than free $\mathrm{CaO}$, respectively; these terms can be determined from the amount of chemically bound water consumed in the Portland cement hydration, the reaction of free $\mathrm{CaO}$ in $\mathrm{FH}$, and the reaction of phases in $\mathrm{FH}$ other than free $\mathrm{CaO}$, respectively [11].

\subsection{Summary of the Proposed Hydration Model of Cement-FH Blends}

Papadakis [11] proposed a chemical-based steady-state model that can be used to evaluate the final chemical and volumetric composition of concrete containing high-calcium fly ash. However, on a construction site, the workers and designers are interested in not only the final properties of the FH concrete but also the evolution of the properties of the FH concrete over time. In this paper, by combining Papadakis' chemical-based steady-state model and the kinetic reaction mechanisms involved in cement hydration and FH reaction, a kinetic model is uniquely proposed to describe the hydration process of $\mathrm{FH}$ concrete. (The mathematical equations shown in sections 2.3 and 2.4 are our original work.) The FH reactions are treated separately from the Portland cement, and some interactions are taken into account through the free water content and the calcium hydroxide content. The proposed model considers the influence of the water to binder ratio, the FH to cement ratio, the mineral compositions and the particle size of cement and FH, and the curing conditions on hydration. Based on the degree of hydration, the development of early-age properties and the durability aspect of FH concrete can be predicted.

The flow chart for a numerical simulation process is shown in Figure 1. The proposed model considers the influences of the Portland cement hydration, the reaction of free $\mathrm{CaO}$ in $\mathrm{FH}$, and the reaction of phases in $\mathrm{FH}$ other than free $\mathrm{CaO}$ on the property developments of cement-FH blends. Using the degree of hydration of cement $\alpha$, the reaction degree of free $\mathrm{CaO}$ in $\mathrm{FH} \alpha_{\mathrm{CF}}$, and the reaction degree of phases in $\mathrm{FH}$ other than free $\mathrm{CaO} \alpha_{\mathrm{FH}}$ at each time step, the amount of calcium hydroxide, capillary water, chemically bound water, porosity, $\mathrm{CSH}$, and compressive strength can be calculated. 


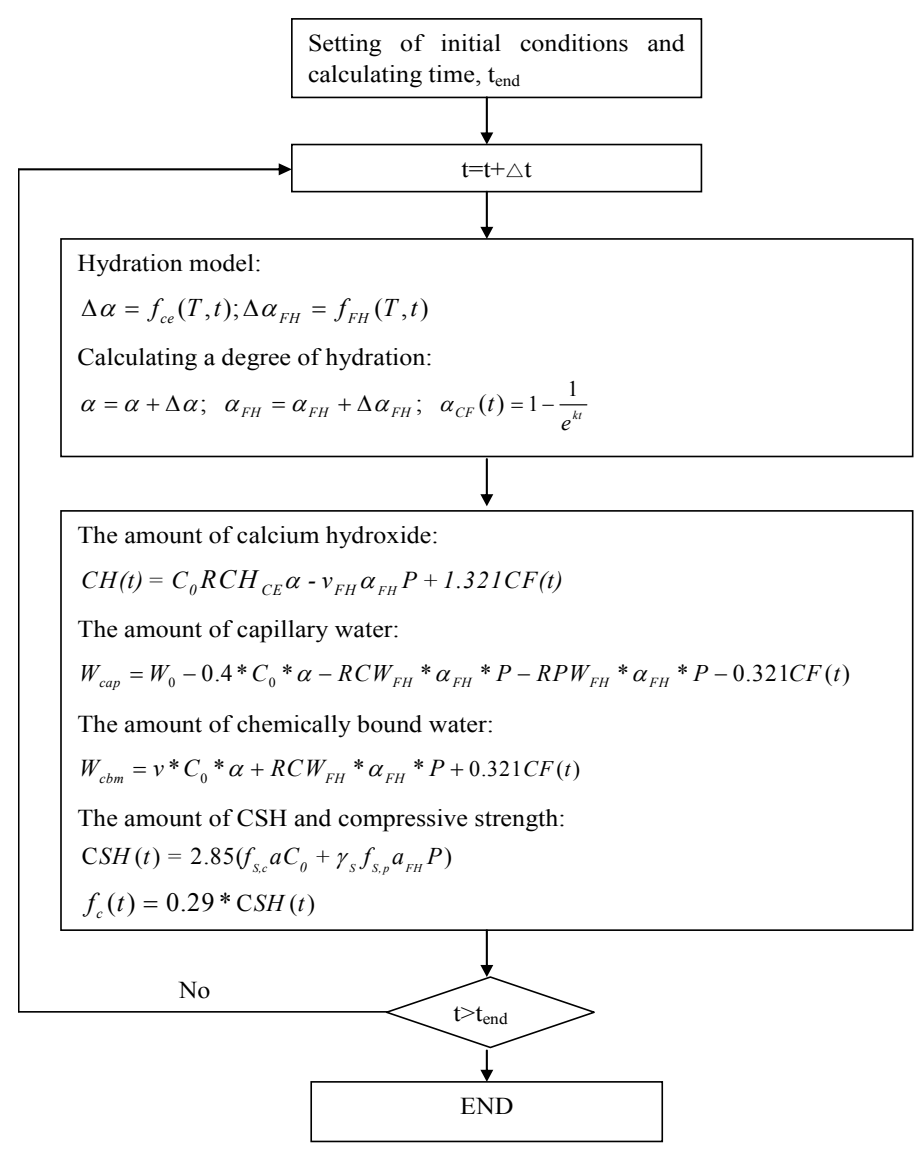

Figure 1. The flow chart for a numerical simulation process.

\section{Verification of the Proposed Model}

Experimental results from reference [11] are used to verify the proposed model. Papadakis [11] studied property developments of high-calcium fly ash blended mortars. A rapid-setting Portland cement was used (400 $\mathrm{m}^{2} / \mathrm{kg}$ Blaine's fineness). Prior to use, high-calcium fly ash was pulverized to meet the cement mean particle size. The physical properties and chemical compositions of cement and FH are shown in Table 2. The total $\mathrm{CaO}$ content in $\mathrm{FH}$ is $23 \%$, the free $\mathrm{CaO}$ content in $\mathrm{FH}$ is $5 \%$, and the glass content in $\mathrm{FH}$ is $50 \%$. The mixture proportions are given in Table 3. In the control specimen, the water-cement ratio $(W / C)$ was 0.5 and the aggregate-cement ratio $(A / C)$ was 3 . Two different cases were studied: FH replaces either aggregate or cement. When $\mathrm{FH}$ replaces aggregate, three contents of $\mathrm{FH}$ were selected: $10 \%, 20 \%$, and $30 \%$ additions to the control cement weight for specimens FHA, 10\%, FHA, 20\%, and FHA, 30\%, respectively. When FH replaces the cement, the same FH contents were selected: $10 \%, 20 \%$, and $30 \%$ replacements of the control cement weight for specimens FHC, 10\%, FHC, 20\%, and FHC, 30\%, respectively.

The developments of strength, porosity, bound water, and calcium hydroxide were measured [11]. The specimens for the strength measurements were prisms of $40 \times 40 \times 160 \mathrm{~mm}$, cured under lime-saturated water at $20^{\circ} \mathrm{C}$ and tested after $3,14,28,49,91,182$, and 364 days. FH-cement pastes were also prepared, representing the paste matrix of the mortar specimens, and analyzed for $\mathrm{CH}$ content, chemically bound water content, and porosity at 3, 7, 14, 28, 49, 112, 182, and 364 days after casting and moist curing [11]. For each test, the moist-cured paste specimen was stripped, placed in a pre-weighed glass mortar, and 
pulverized. The mortar with the material was placed in an oven at $105^{\circ} \mathrm{C}$ until the weight was constant. These weight indications were used to determine the chemically bound water content and porosity. To determine the $\mathrm{CH}$ content, a paste sample of the oven-dried powder was examined by a combination of quantitative X-ray diffraction analysis and TG/DTA (thermogravimetry/differential thermal analysis). The mass loss corresponding to the decomposition of $\mathrm{Ca}(\mathrm{OH})_{2}$ occurs between $440{ }^{\circ} \mathrm{C}$ and $520{ }^{\circ} \mathrm{C}$. The paste properties were reduced to the corresponding mortar specimen volume by multiplying the appropriate paste volume/mortar volume fraction [11].

Table 2. Physical and chemical characteristic of cement and FH.

\begin{tabular}{ccc}
\hline Properties & Cement & FH \\
\hline Physical properties & - & - \\
BET specific surface $\left(\mathrm{m}^{2} / \mathrm{g}\right)$ & 1.3 & 6.2 \\
Particle mean diameter $(\mu \mathrm{m})$ & 14.0 & 12.6 \\
Density $\left(\mathrm{kg} / \mathrm{m}^{3}\right)$ & 3130 & 2660 \\
Chemical analysis $(\%)$ & - & - \\
$\mathrm{SiO}_{2}$ & 20.10 & 39.21 \\
$\mathrm{Al}_{2} \mathrm{O}_{3}$ & 4.25 & 16.22 \\
$\mathrm{Fe}_{2} \mathrm{O}_{3}$ & 3.49 & 6.58 \\
& & 22.78 \\
$\mathrm{CaO}$ & 63.20 & 5.18 \\
$\mathrm{SO}_{3}$ & & free $)$ \\
$\mathrm{LOI}$ & 2.88 & 4.3 \\
& 0.86 & 2.10 \\
\hline
\end{tabular}

Table 3. Mixing proportions of the specimens.

\begin{tabular}{cccccccc}
\hline Specimens & $\begin{array}{c}\text { Cement } \\
\left(\mathbf{k g} / \mathbf{m}^{\mathbf{3}}\right)\end{array}$ & $\begin{array}{c}\text { Water } \\
\left(\mathbf{k g} / \mathbf{m}^{\mathbf{3}}\right)\end{array}$ & $\begin{array}{c}\text { FH } \\
\left(\mathbf{k g} / \mathbf{m}^{\mathbf{3}}\right)\end{array}$ & $\begin{array}{c}\text { Aggregate } \\
\left(\mathbf{k g} / \mathbf{m}^{\mathbf{3}}\right)\end{array}$ & $\begin{array}{c}\text { Water to } \\
\text { Binder } \\
\text { Ratio }\end{array}$ & $\begin{array}{c}\text { FH to } \\
\text { Cement } \\
\text { Ratio }\end{array}$ & $\begin{array}{c}\text { Aggregate } \\
\text { to Cement } \\
\text { Ratio }\end{array}$ \\
\hline control & 514.6 & 257.4 & 0 & 1543.8 & 0.5 & 0 & 3 \\
FHA, 10\% & 514.6 & 257.4 & 51.5 & 1492.1 & 0.46 & 0.1 & 2.9 \\
FHA, 20\% & 514.6 & 257.4 & 102.9 & 1440.5 & 0.42 & 0.2 & 2.8 \\
FHA, 30\% & 514.6 & 257.4 & 154.4 & 1388.8 & 0.39 & 0.3 & 2.7 \\
FHC, 10\% & 463.1 & 257.4 & 51.5 & 1536.0 & 0.5 & 0.11 & 3.32 \\
FHC, 20\% & 411.7 & 257.4 & 102.9 & 1528.3 & 0.5 & 0.25 & 3.71 \\
FHC, 30\% & 360.2 & 257.4 & 154.4 & 1520.5 & 0.5 & 0.43 & 4.22 \\
\hline
\end{tabular}

\subsection{Evaluation of Calcium Hydroxide Contents}

In the proposed model, the reaction of free $\mathrm{CaO}$ and other phases in $\mathrm{FH}$ are simulated separately. Equation (3) is used to model the rapid reaction of free $\mathrm{CaO}$ in $\mathrm{FH}$, and Equation (4) is used to model the reaction of phases in $\mathrm{FH}$ other than free $\mathrm{CaO}$. Using the chemical analysis of $\mathrm{FH}$ shown in Table 2, 
we can determine the weight fractions of $\mathrm{S}, \mathrm{A}, \mathrm{C}$, and $\overline{\mathrm{S}}$ in the $\mathrm{FH}$ other than free $\mathrm{CaO}$. Furthermore, the active part of $\mathrm{FH}$ other than free $\mathrm{CaO}, \gamma_{\text {active }}$, which includes an aluminosilicate glass phase, a calcium phase, and a sulfate phase, can be calculated. The weight fractions of FH used for modeling are shown in Table 4.

Using the experimental results of calcium hydroxide from Portland cement and a predictor-corrector algorithm [19], the reaction coefficients of Portland cement $B_{\mathrm{ce}}, C_{\mathrm{ce}}, D_{\mathrm{e} 0}$, and $k_{\mathrm{r}}$ can be determined. Using the experimental results of calcium hydroxide from cement-FH paste, the FH reaction coefficients $B_{\mathrm{FH}}, C_{\mathrm{FH}}, D_{\mathrm{e} 0 \mathrm{FH}}$, and $k_{\mathrm{rFH}}$ can be determined. The values of the reaction coefficients are shown in Table 5. The fit parameters for a material are not changed from one mix to the other. For concrete with different water to binder ratios or FH replacement ratios, the reaction coefficients of cement and FH do not change.

Table 4. Weight fractions of FH.

\begin{tabular}{ccccccc}
\hline$\gamma_{\mathbf{S}}$ & $\boldsymbol{f}_{\mathbf{S}, \mathbf{p}}$ & $\gamma_{\mathbf{A}}$ & $\boldsymbol{f}_{\mathbf{A}, \mathbf{p}}$ & $f_{\overline{\mathbf{S}}, \mathbf{p}}$ & $\boldsymbol{f}_{\mathbf{C}, \mathbf{p}}$ & $\mathbf{C a O}_{\text {free }}$ \\
\hline 0.7 & 0.413 & 0.7 & 0.1711 & 0.0453 & 0.1856 & 0.0518 \\
$\gamma_{\text {active }}=\gamma_{\mathrm{S}} f_{\mathrm{S}, \mathrm{p}}\left(1-\mathrm{CaO}_{\text {free }}\right)+\gamma_{\mathrm{A}} f_{\mathrm{A}, \mathrm{p}}\left(1-\mathrm{CaO}_{\text {free }}\right)+f_{\mathrm{C}, \mathrm{p}}\left(1-\mathrm{CaO}_{\text {free }}\right)+f_{\overline{\mathrm{S}}, \mathrm{p}}\left(1-\mathrm{CaO}_{\text {free }}\right)$ & 0.61 \\
\hline
\end{tabular}

Table 5. Coefficients of the reaction model.

\begin{tabular}{cccc}
\hline $\boldsymbol{B}_{\mathbf{c e}}(\mathbf{c m} / \mathbf{h})$ & $\boldsymbol{C}_{\mathbf{c e}}(\mathbf{c m} / \mathbf{h})$ & $\boldsymbol{k}_{\mathbf{r}}(\mathbf{c m} / \mathbf{h})$ & $\boldsymbol{D}_{\mathbf{e} 0}\left(\mathbf{c m}^{\mathbf{2}} \mathbf{h}\right)$ \\
\hline $1 \times 10^{-8}$ & 0.81 & $2.33 \times 10^{-6}$ & $3.79 \times 10^{-10}$ \\
$B_{\mathrm{FH}}(\mathrm{cm} / \mathrm{h})$ & $C_{\mathrm{FH}}(\mathrm{cm} / \mathrm{h})$ & $k_{\mathrm{rFH}}(\mathrm{cm} / \mathrm{h})$ & $D_{\mathrm{e} 0 \mathrm{FH}}\left(\mathrm{cm}^{2} / \mathrm{h}\right)$ \\
$2.22 \times 10^{-11}$ & 0.08 & $5.45 \times 10^{-7}$ & $2 \times 10^{-8}$ \\
\hline
\end{tabular}

After calibrating the coefficients of the reaction model, multiple checks, such as the evolution of chemically bound water, porosity, CSH contents, and compressive strength, were performed to verify the proposed model. The procedure of the proposed model is similar to that of Tomosawa et al. $[15,19]$. In Tomosawa's model, the heat evolution of Portland cement was adopted to calibrate the coefficients of the hydration model. Furthermore, the evolution of the mechanical properties in early-age concrete was described using functions of the degree of hydration [15,19].

The evaluation results of the calcium hydroxide contents are shown in Figure 2. The $\mathrm{CH}$ content of the control specimen increases with time until a steady state is attained (Figure 2a). The CH content of FHA specimens presents a rather complicated picture due to the simultaneous $\mathrm{CH}$ production from the reaction of cement and the free $\mathrm{CaO}$ and $\mathrm{CH}$ consumption from other phases of the $\mathrm{FH}$. In the first week, due to the rapid free $\mathrm{CaO}$ hydration, the $\mathrm{CH}$ contents are higher in the fly ash specimens (Figure $2 \mathrm{~b}-\mathrm{d}$ ) than that of the control specimen (Figure 2a), These $\mathrm{CH}$ contents pass through a maximum due to higher $\mathrm{CH}$ production but decrease afterward as the $\mathrm{FH}-\mathrm{CH}$ reaction proceeds at higher rates. At a late age, with the FH replacing ratio increasing from $10 \%$ to $30 \%$, the $\mathrm{CH}$ contents decrease correspondingly. For concrete with $10 \%$ FH (Figure 2c) and 20\% FH (Figure 2b), at the age of one year, the calcium hydroxide will slightly increase. This result may be due to the depletion of the active part of FH. Because the proposed model has modeled the rapid production of calcium hydroxide from the free $\mathrm{CaO}$ reaction in $\mathrm{FH}$, the production of calcium hydroxide from cement hydration, and the consumption of calcium hydroxide 
from other phase reactions in $\mathrm{FH}$, the proposed model can describe the complicated evolution process of cement-FH blends. Figure 2e shows the comparison between the experimental results and the analysis results for different mixing proportions. The correlation coefficient between the experimental results and the analysis results is 0.95 .

In addition, Figure 2 shows the analysis results of calcium hydroxide from Papadakis' model [11]. Papadakis assumed that at the age of 365 days, the reaction rate of cement and FH is very slow. The age of 365 days can be approximately regarded as the steady state age of FH blended concrete. As shown in Figure 2, Papadakis' model can calculate the final CH content. However, because Papadakis' model does not consider the kinetic reaction process of $\mathrm{FH}$, this model cannot calculate the evolution of $\mathrm{CH}$ in cement-FH blends. The calculation result of Papadakis' model is a point, not a curve. Conversely, the calculation result from our kinetic hydration model is a curve.

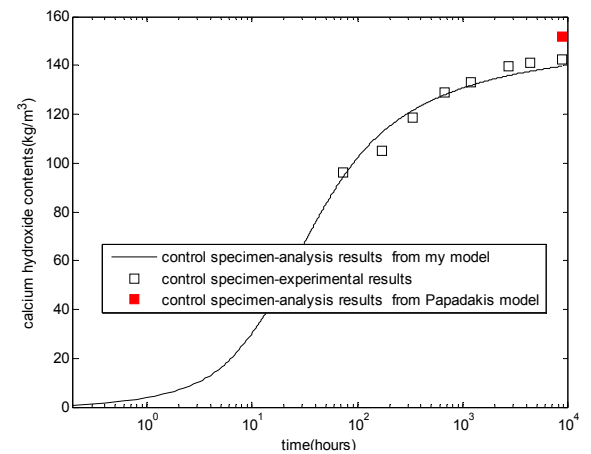

(a)

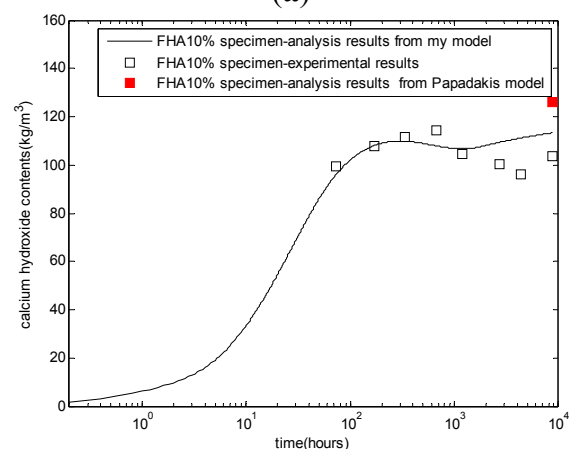

(c)

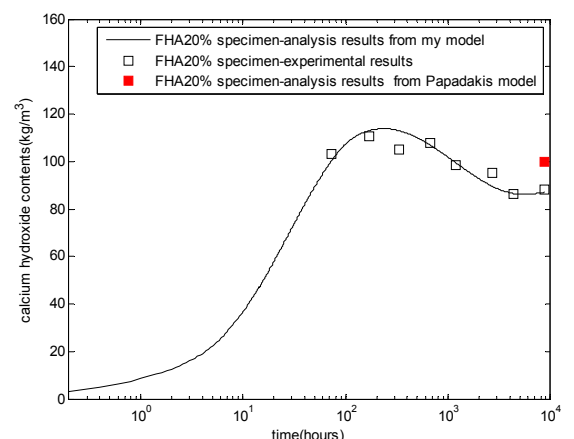

(b)

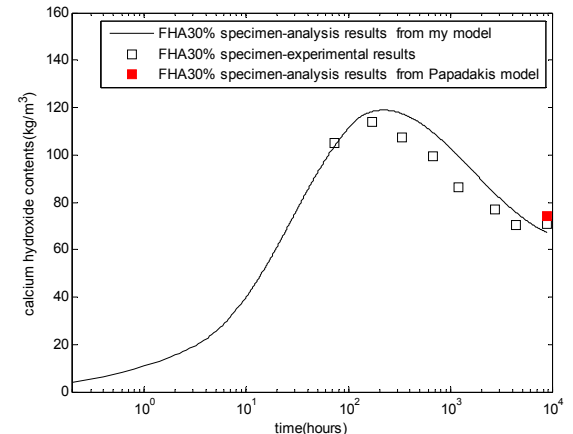

(d)

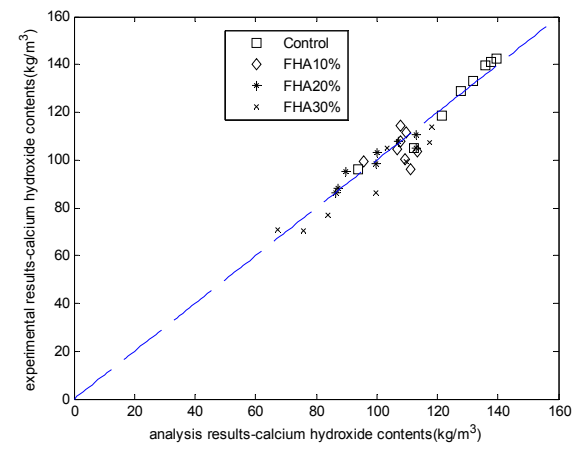

(e)

Figure 2. Development of calcium hydroxide contents. (a) Control concrete; (b) FHA, 20\% concrete: FH replaces aggregate by $20 \%$ weight of cement; (c) FHA, 10\% concrete: FH replaces aggregate by $10 \%$ weight of cement; (d) FHA, 30\% concrete: FH replaces aggregate by $30 \%$ weight of cement; (e) comparison between analysis results and experimental results. 
The evaluation of the reaction degree of fly ash $\alpha_{\text {FH-total }}$ is shown in Figure 3 . As shown in this figure, given a certain water to binder ratio, with an increasing replacement level of fly ash, the alkaline-activating effect of the cement would be weaker, so that the reactivity of the fly ash decreases [20]. Conversely, at a late age, for concrete with $10 \%$ and $20 \% \mathrm{FH}$, the active part of $\mathrm{FH}$ has totally reacted (the ultimate reaction degree equals the weight fraction of the active part $\gamma_{\text {active }}$ ). For concrete with $30 \% \mathrm{FH}$, until the age of one year, part of FH is still un-reacted.

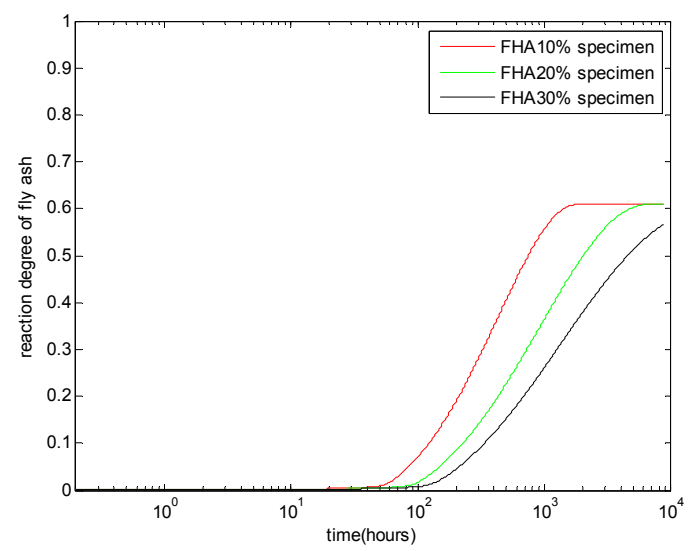

Figure 3. Reaction degree of high-calcium fly ash with different FH contents: FH replaces aggregate by $10 \%, 20 \%$, and $30 \%$ weight of cement and a water to binder ratio of 0.5 .

\subsection{Evaluation of Chemically Bound Water and Porosity}

The evaluation results of chemically bound water and porosity contents are shown in Figures 4 and 5 respectively. A higher chemically bound water $(\mathrm{H})$ content (Figure 4) and a lower porosity (Figure 5) is observed for all of the FHA specimens compared to the corresponding control values from the initiation of the cement hydration. This increase in $\mathrm{H}$ values or the similar decrease in porosity values is almost proportional to the fly ash content in the specimen. This behavior can be partly explained as being due to the presence of free $\mathrm{CaO}$ in the $\mathrm{FH}$ and the hydration of the tricalcium aluminate present in $\mathrm{FH}$. The early formation of water-rich and pore-filling ettringite and its subsequent transformation to other hydrates contributes significantly to the increased hydration and decreased porosity [11].

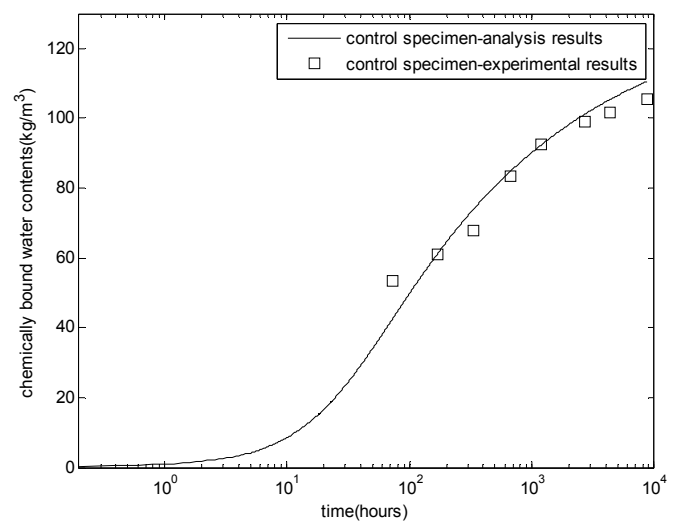

(a)

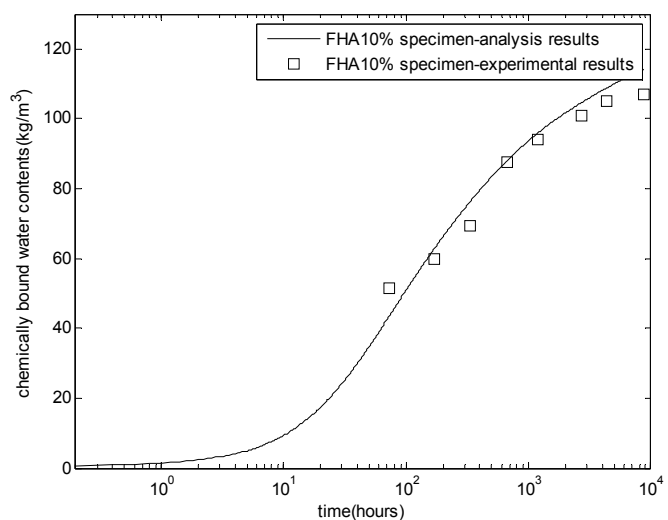

(b)

Figure 4. Cont. 


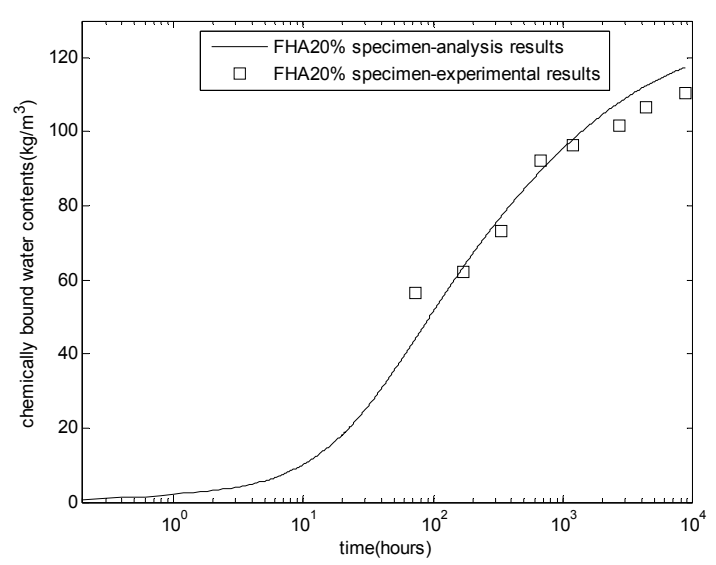

(c)

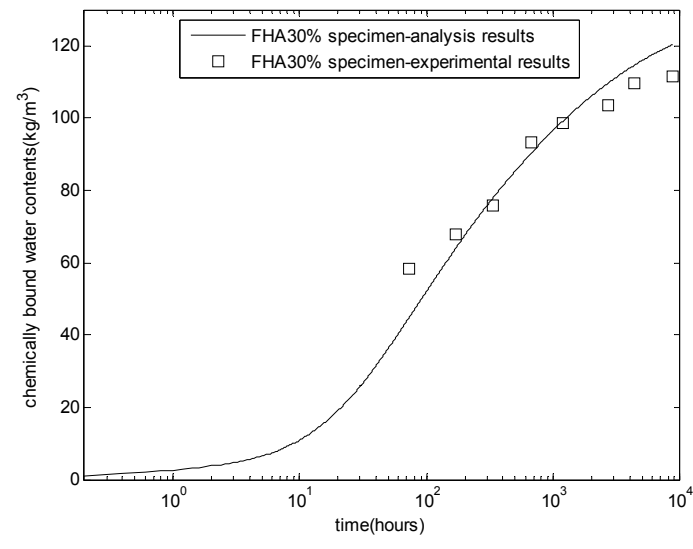

(d)

Figure 4. Development of chemically bound water contents. (a) Control concrete; (b) FHA10\% concrete: FH replaces aggregate by 10\% weight of cement; (c) FHA20\% concrete: FH replaces aggregate by $20 \%$ weight of cement; (d) FHA30\% concrete: FH replaces aggregate by $30 \%$ weight of cement.

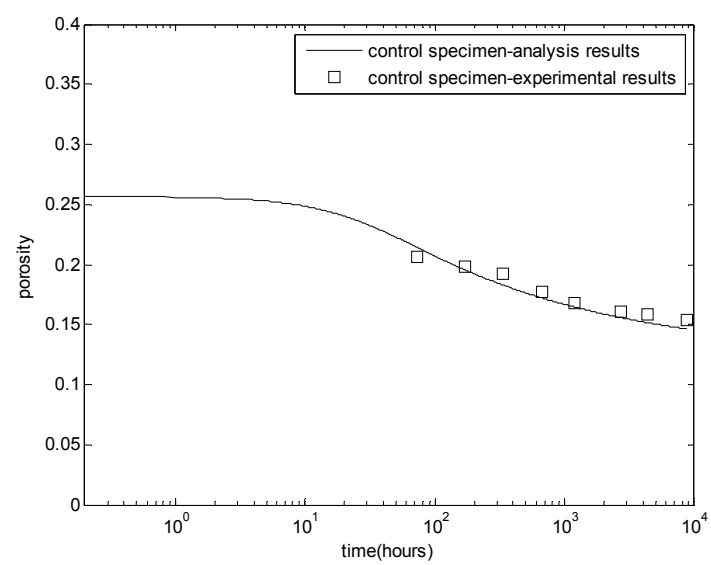

(a)

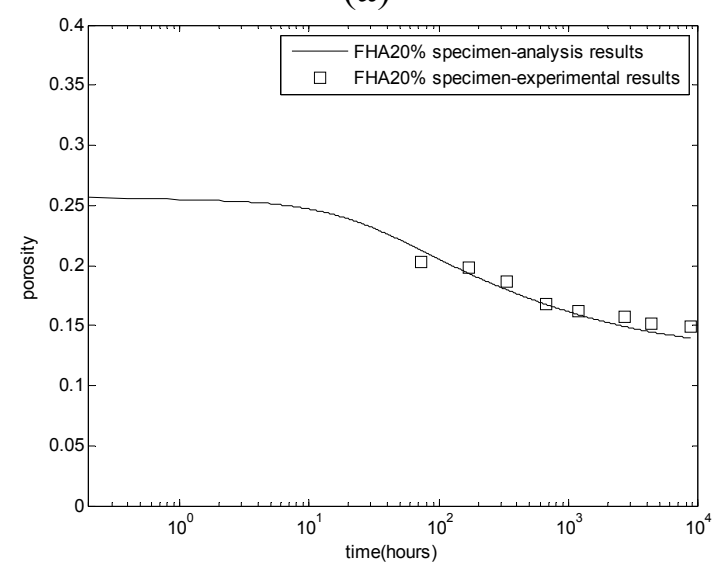

(c)

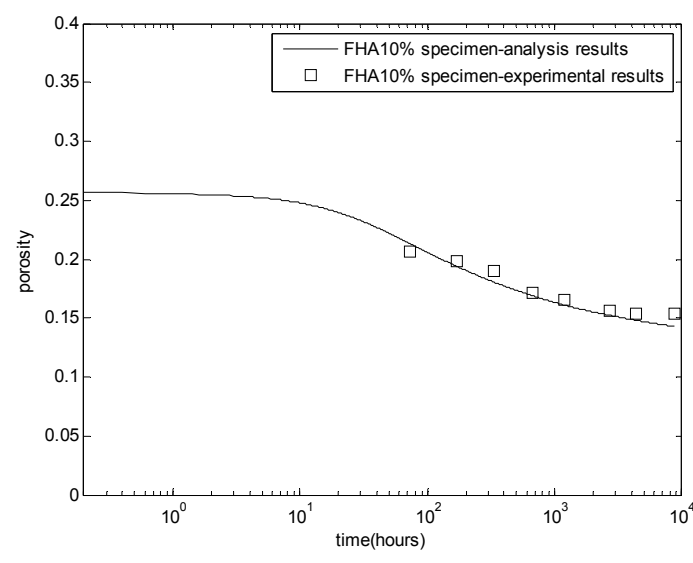

(b)

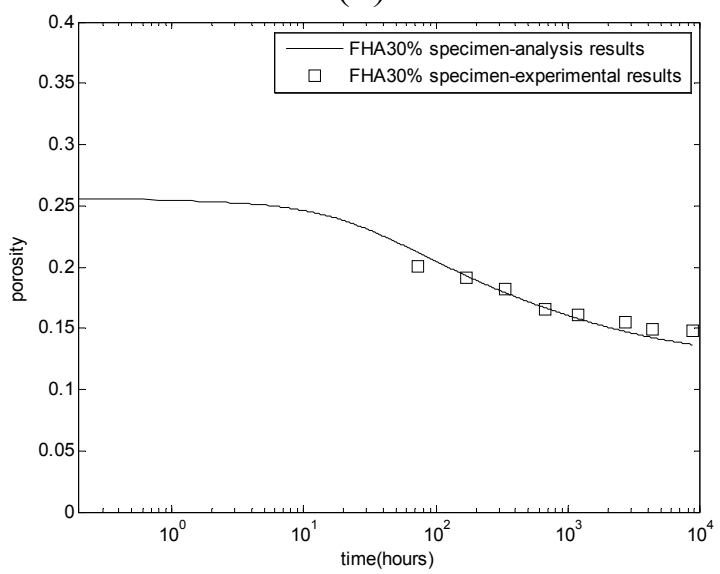

(d)

Figure 5. Development of porosity contents. (a) Control concrete; (b) FHA10\% concrete: FH replaces aggregate by $10 \%$ weight of cement; (c) FHA20\% concrete: FH replaces aggregate by $20 \%$ weight of cement; (d) FHA30\% concrete: FH replaces aggregate by $30 \%$ weight of cement. 


\subsection{Evaluation of Compressive Strength}

Papadakis [11,12] proposed that the compressive strength of cement-based materials, such as concrete containing low-calcium fly ash, high-calcium fly ash, and slag, can be estimated from the CSH content. Using the proposed hydration model considering both cement hydration and $\mathrm{FH}$ reaction (Equation (8d)), we can calculate the $\mathrm{CSH}$ contents for mortars with different FH contents, such as the control specimen, FHA, $10 \%$ (FH replaces aggregate by $10 \%$ weight of cement), FHA, 20\% (FH replaces aggregate by $20 \%$ weight of cement), FHA30\% (FH replaces aggregate by $30 \%$ weight of cement), and FHC, 20\% (FH replaces cement by 20\%). Figure 6 presents the compressive strength of the FH blended mortars as a function of the calculated CSH contents. As shown in Figure 6, for concrete with different FH contents (control, FHA, 10\%, FHA, 20\%, FHA, 30\%, and FHC, 20\%) and at different ages (3, 14, 28, 49, 91, 182, and 364 days), a single linear relationship exists between the compressive strengths and the calculated $\mathrm{CSH}$ amounts, i.e., the compressive strength $=0.29 \times \mathrm{CSH}$.

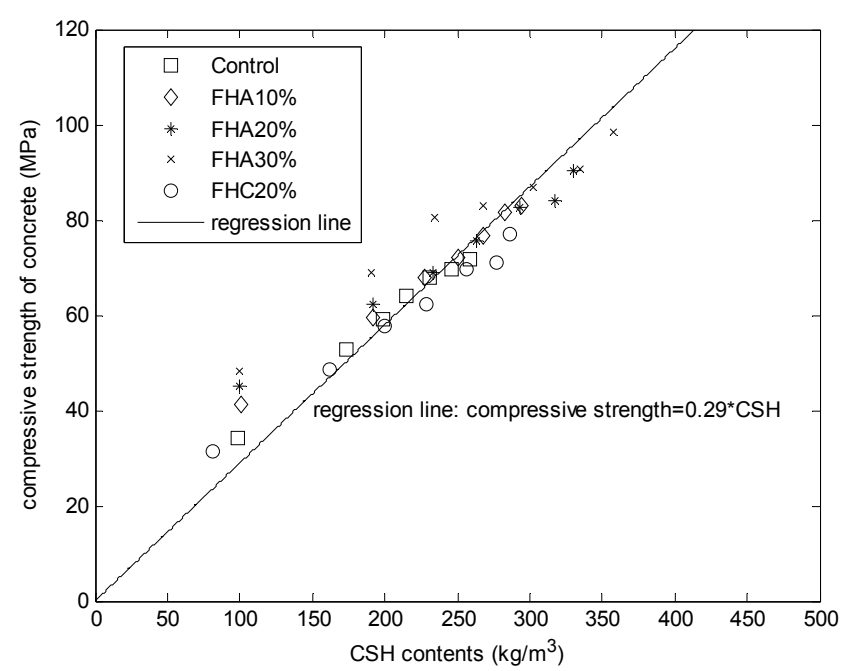

Figure 6. Compressive strength of mortars as a function of calculated $(\mathrm{CSH})$ content.

Using the regressed linear relationship between the compressive strength and the CSH content, we can evaluate the development of the compressive strength of FH-cement blends. Figure 7 shows the comparison between the experiment results and the simulation results of the compressive strength. For mortar containing FH-replacing aggregate (FHA mortars, as shown in Figure 7b-d), the compressive strength of FHA specimens is higher than that of the control specimen (Figure 7a) since the early ages. However, for mortar containing FH-replacing cement (FHC mortar, as shown in Figure 7e), at early ages, the compressive strength of the FHC specimen is lower than that of the control specimen (Figure 7a), and at late ages, due to the evolution of the FH reaction, the compressive strength of the FHC specimen surpasses that of the control specimen. Conversely, in the early age of three days, the simulation value is slightly lower than the experimental value. This result may be due to the omission of some factors, such as the contribution of ettringite from the FH reaction [11] and the nucleation effects of FH [11]. For FHA, 30\% concrete (Figure 7d), due to the abundant ettringite produced from the FH reaction, at the early ages of three and 14 days, the analysis results show more deviations from the experimental results than for the other mixing proportions. 


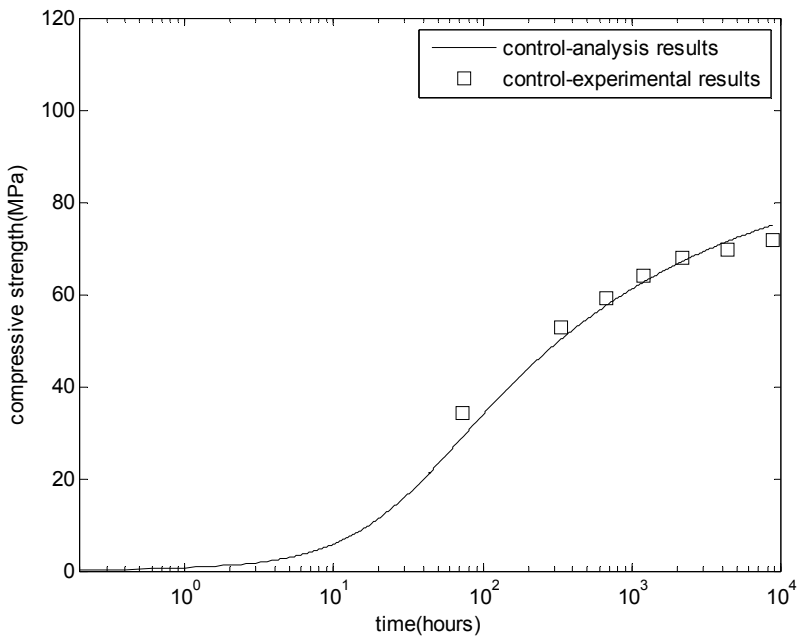

(a)

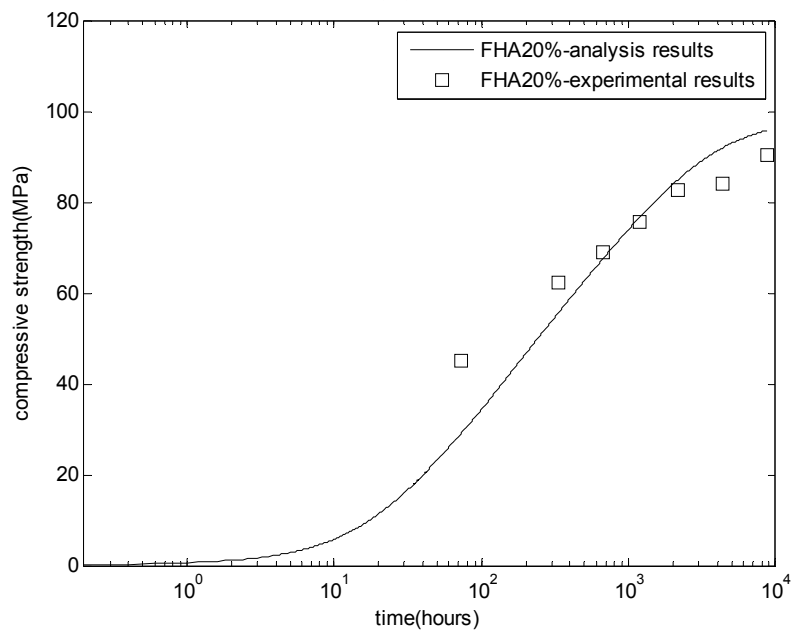

(c)

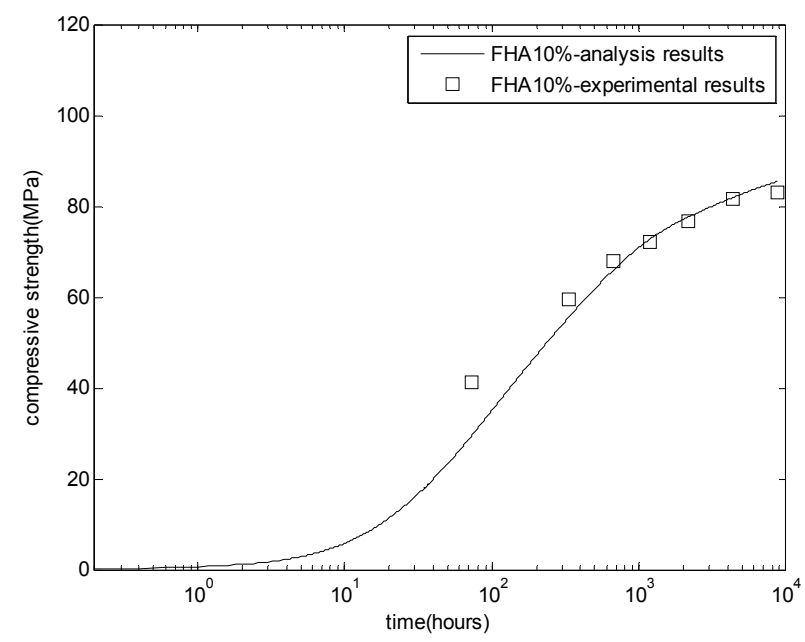

(b)

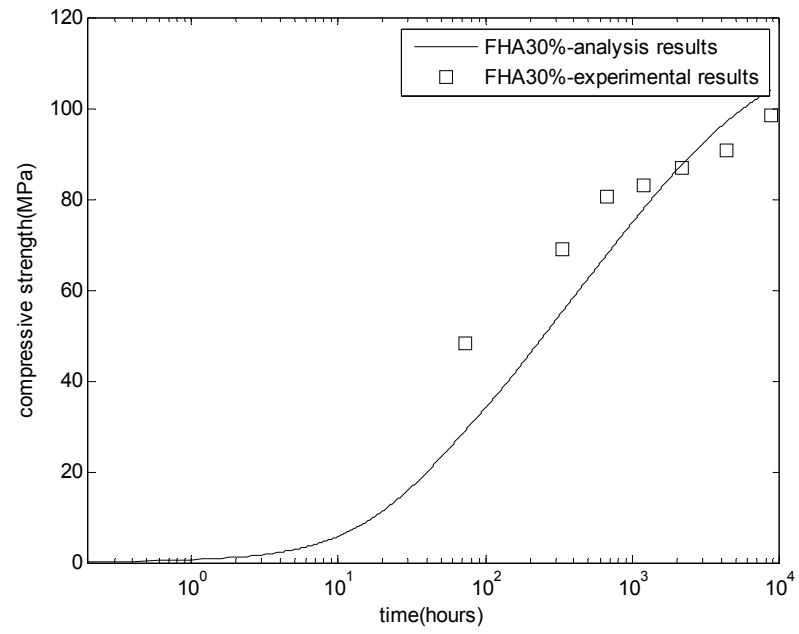

(d)

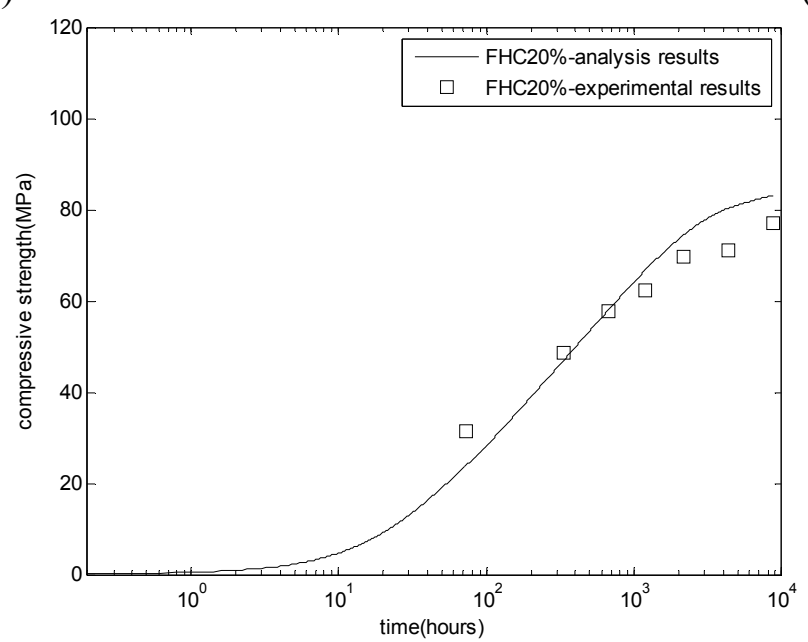

(e)

Figure 7. Evaluation of the compressive strength of FH concrete. (a) Control concrete; (b) FHA, 10\% concrete: FH replaces aggregate by 10\% weight of cement; (c) FHA, 20\% concrete: FH replaces aggregate by $20 \%$ weight of cement; (d) FHA, 30\% concrete: FH replaces aggregate by 30\% weight of cement; (e) FHC, 20\% concrete: FH replaces cement by $20 \%$. 
In addition, the free $\mathrm{CaO}$ in $\mathrm{FH}$ also affects the compressive strength developments of hardening cement-FH blends. Tsimas and Moutsatsou-Tsima [7] investigated the influence of free $\mathrm{CaO}$ contents on the compressive strength development. When the free $\mathrm{CaO}$ content increases from $1.8 \%$ to $3.5 \%$, the compressive strength will increase correspondingly. This result is mainly due to the stimulus of the free $\mathrm{CaO}$ on the initial $\mathrm{FH}$ reaction [7]. However, when the free $\mathrm{CaO}$ content further increases from 3.5\% to $6.8 \%$, the soundness of the concrete will be impaired and the compressive strength will decrease. Therefore, the free $\mathrm{CaO}$ presents double-edged effects on the strength development. For the model proposed in this paper, further investigations should be performed regarding FH with various chemical compositions and free $\mathrm{CaO}$ contents.

In the concrete industry, considering the economic and environmental effects, high-calcium fly ash is generally used as a mineral admixture to replace cement. Using the hydration model, we can calculate the $\mathrm{CSH}$ contents. Furthermore, using the regressed linear relationship between the compressive strengths and $\mathrm{CSH}$ amounts, we can calculate the compressive strength development of FH concrete. Figure 8 shows the analysis results of the compressive strength of FH blended concrete with a water to binder ratio of 0.5 and different FH contents: FH replacing cement by 10\%, 20\%, and 30\%. The proposed model can reproduce the compressive strength crossover phenomenon between the control Portland cement concrete and the FH blended concrete. With increasing FH replacement ratios, the reactivity of FH will decrease (as shown in Figure 3) and the age corresponding to the crossover of the compressive strength will be postponed.

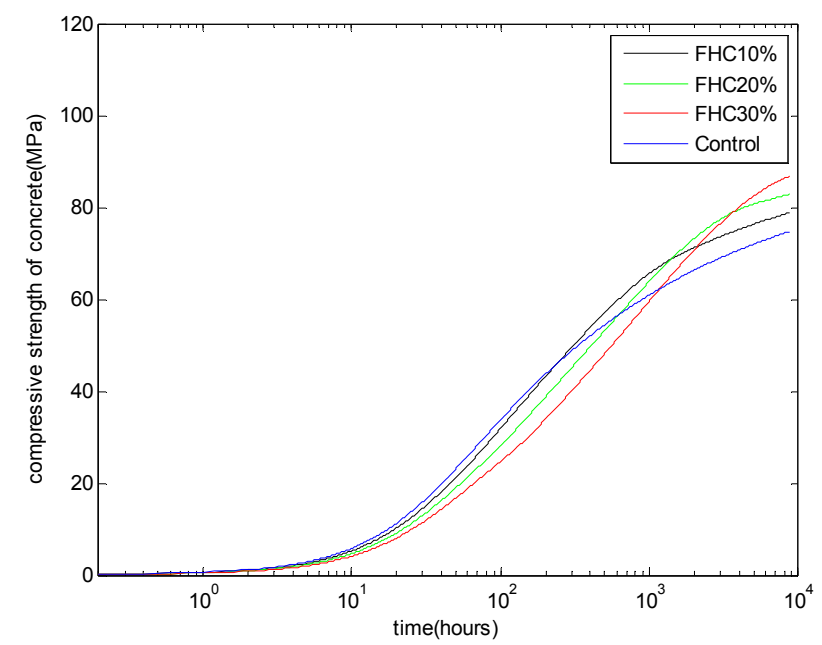

Figure 8. Compressive strength development of FH concrete: water to binder ratio of 0.5 and $\mathrm{FH}$ replaces cement by $10 \%, 20 \%$, and $30 \%$.

Figure 9 shows the compressive strength development of $\mathrm{FH}$ blended concrete with different FH contents (FH replaces cement by $10 \%$ to $70 \%$ ) at different ages of seven days, 28 days, 90 days, and 365 days. At an early age of seven days, compared to the control concrete, the compressive strength of FH concrete almost linearly decreases with increasing FH content. With increasing curing age, due to the development of the FH reaction, the compressive strength of FH concrete will surpass that of the control concrete. However, for concrete incorporating larger FH contents (more than 50\% cement is replaced by $\mathrm{FH}$ ), due to the reduction of FH reactivity, at the age of one year, the compressive strength of $\mathrm{FH}$ 
concrete is still lower than that of the control concrete. Therefore, 50\% can be regarded as the maximum replacement ratio of FH. Over this maximum replacement ratio, the compressive strength of FH blended concrete will be lower than that of the control concrete. Conversely, at the age of one year, when the FH replacement ratio is higher than $30 \%$, the compressive strength of concrete will decrease. Therefore, $30 \% \mathrm{FH}$ can be regarded as an optimum FH content for concrete incorporating FH as a cement-replacing mineral admixture. The optimum FH content can be explained as follows: according to Equation (8d), the $\mathrm{CSH}$ content produced from the $\mathrm{FH}$ reaction, $2.85 \gamma_{\mathrm{S}} f_{\mathrm{s}, \mathrm{p}} \alpha_{\mathrm{FH}} P$, relates to the $\mathrm{FH}$ content $P$ and the reaction degree of $\mathrm{FH} \alpha_{\mathrm{FH}}$. With increasing $\mathrm{FH}$ content $P$, the reactivity of $\mathrm{FH}$ will decrease (as shown in Figure 3), and therefore, there is a peak value for the product of $\mathrm{FH}$ content $P$ and the reaction degree of $\mathrm{FH} \alpha_{\mathrm{FH}}$. The FH content corresponding to the peak value can be regarded as the optimum replacement of $\mathrm{FH}$.

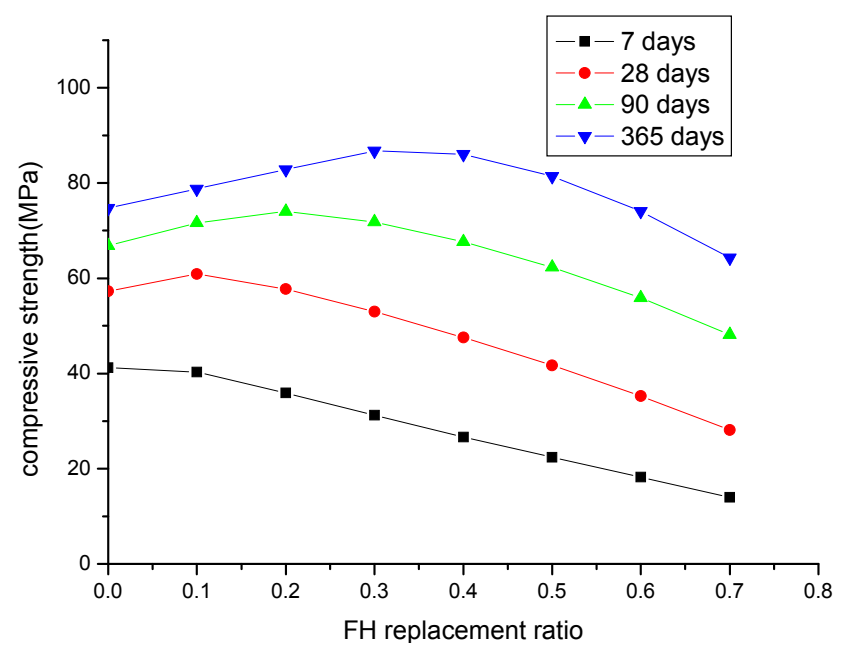

Figure 9. Parameter analysis of the compressive strength of concrete: a water to binder ratio of 0.5 and $\mathrm{FH}$ replaces cement by $10 \%$ to $70 \%$.

\section{Conclusions}

(1) This paper proposes a numerical procedure to simulate the hydration of cement and high-calcium fly ash (FH) blends. The hydration of cement, the reaction of free $\mathrm{CaO}$ in $\mathrm{FH}$, and the reaction of phases in $\mathrm{FH}$ other than free $\mathrm{CaO}$ are modeled. The interactions among the hydration of cement, the reaction of free $\mathrm{CaO}$ in $\mathrm{FH}$, and the reaction of phases in $\mathrm{FH}$ other than free $\mathrm{CaO}$ are considered through the available calcium contents and capillary water contents in the system. The reaction of free $\mathrm{CaO}$ in $\mathrm{FH}$ is described as a first-order reaction. The reaction of other phases in FH is divided into three processes, i.e., an initial dormant period, a phase boundary reaction process, and a diffusion process. The reaction coefficients of other phases in FH are obtained from experimental results of calcium hydroxide in cement-FH blends. The fit parameters for a material are not changed from one mix to the other. For concrete with different water to binder ratios or FH replacement ratios, the reaction coefficients of cement and FH do not change.

(2) Using the numerical procedure, the hydration degree of cement, the reaction degree of free $\mathrm{CaO}$ in $\mathrm{FH}$, and the reaction degree of phases in $\mathrm{FH}$ other than free $\mathrm{CaO}$ are calculated. The amount of calcium hydroxide, bound water, porosity, and compressive strength of FH blended concrete are determined considering the contributions from the hydration of cement, the reaction of free $\mathrm{CaO}$ in $\mathrm{FH}$, 
and the reaction of phases in $\mathrm{FH}$ other than free $\mathrm{CaO}$. At different curing ages, for $\mathrm{FH}$ blended concrete with different FH contents, a single linear relationship exists between the compressive strengths and the calculated CSH amounts. The proposed model can reproduce the compressive strength crossover phenomenon between control Portland cement concrete and FH blended concrete. The proposed model also can be used to determine the optimum content of FH.

\section{Acknowledgments}

This research was supported by Basic Science Research Program through the National Research Foundation of Korea (NRF) funded by the Ministry of Science, ICT \& Future Planning (No. 2015R1A5A1037548).

\section{Author Contributions}

Wei-jie Fan conducted the programming and wrote the initial draft of the manuscript. Xiao-Yong Wang designed the project and analyzed the data. Ki-Bong Park wrote the final manuscript. All of the authors contributed to the analysis of the data and read the final paper.

\section{Conflicts of Interest}

The authors declare no conflict of interest.

\section{References}

1. Metha, P.K.; Monteiro, P.J.M. Concrete: Microstructure, Properties and Materials; McGraw-Hill: New York, NY, USA, 2006.

2. Wang, Q.; Feng, J.J.; Yan, P.Y. An explanation for the negative effect of elevated temperature at early ages on the late-age strength of concrete. J. Mater. Sci. 2011, 46, 7279-7288. [CrossRef]

3. Hwang, K.; Noguchi, T.; Tomosawa, F. Prediction model of compressive strength development of fly-ash concrete. Cem. Concr. Res. 2004, 34, 2269-2276. [CrossRef]

4. Maekawa, K.; Ishida, T.; Kishi, T. Multi-Scale Modeling of Structural Concrete; Taylor \& Francis: London, UK, 2009.

5. Wang, X.Y.; Lee, H.S. Modeling the hydration of concrete incorporating fly ash or slag. Cem. Concr. Res. 2010, 40, 984-996. [CrossRef]

6. Yu, Z.Q.; Ye, G. The pore structure of cement paste blended with fly ash. Constr. Build. Mater. 2013, 45, 30-35. [CrossRef]

7. Tsimas, S.; Moutsatsou-Tsima, A. High-calcium fly ash as the fourth constituent in concrete: Problems, solutions and perspectives. Cem. Concr. Compos. 2005, 27, 231-237. [CrossRef]

8. Antiohos, S.; Tsimas, S. Investigating the role of reactive silica in the hydration mechanisms of high-calcium fly ash/cement systems. Cem. Concr. Compos. 2005, 27, 171-181. [CrossRef]

9. Erdoğdu, K.; Türker, P. Effects of fly ash particle size on strength of portland cement fly ash mortars. Cem. Concr. Res. 1998, 28, 1217-1222. [CrossRef]

10. Papadakis, V.G.; Pedersen, E.J.; Lindgreen, H. An AFM-SEM investigation of the effect of silica fume and fly ash on cement paste microstructure. J. Mater. Sci. 1999, 34, 683-690. [CrossRef] 
11. Papadakis, V.G. Effect of fly ash on Portland cement systems: Part II. High-calcium fly ash. Cem. Concr. Res. 2000, 30, 1647-1654. [CrossRef]

12. Papadakis, V.G.; Tsimas, S. Supplementary cementing materials in concrete Part I: Efficiency and design. Cem. Concr. Res. 2002, 32, 1525-1532. [CrossRef]

13. Schindler, A.K.; Folliard, K.J. Heat of hydration models for cementitious materials. Am. Concr. Inst. Mater. J. 2005, 102, 24-33.

14. Saeki, T.; Monteiro, P.J.M. A model to predict the amount of calcium hydroxide in concrete containing mineral admixture. Cem. Concr. Res. 2005, 35, 1914-1921. [CrossRef]

15. Tomosawa, F. Development of a kinetic model for hydration of cement. In Proceedings of the Tenth International Congress Chemistry of Cement, Gothenburg, Sweden, 2-6 June 1997; pp. 43-50.

16. Park, K.B.; Jee, N.Y.; Yoon, I.S.; Lee, H.S. Prediction of temperature distribution in high-strength concrete using hydration model. Am. Concr.Inst. Mater. J. 2008, 105, 180-186.

17. Chen, R.; Chen, Z.Y. Study on the hydration kinetics of free $\mathrm{CaO}$ in high calcium fly ash. J. Build. Mater. 2000. [CrossRef]

18. Giergiczny, Z. The hydraulic activity of high calcium fly ash. J Therm. Anal. Calorim. 2006, 83, 227-232. [CrossRef]

19. Tomosawa, F.; Noguchi, T.; Hyun, C. Simulation model for temperature rise and evolution of thermal stress in concrete based on kinetic hydration model of cement. In Proceedings of the Tenth International Congress Chemistry of Cement, Gothenburg, Sweden, 2-6 June 1997; pp. 72-75.

20. Chen, W.; Brouwers, H.J.H.; Shui, Z.H. Three-dimensional computer modeling of slag cement hydration. J. Mater. Sci. 2007, 42, 9595-9610. [CrossRef]

(C) 2015 by the authors; licensee MDPI, Basel, Switzerland. This article is an open access article distributed under the terms and conditions of the Creative Commons Attribution license (http://creativecommons.org/licenses/by/4.0/). 